basic law of statistics, the law of large numbers, which predicts increasing accuracy of a mean based on increasing numbers of observations." Now the law of large numbers is concerned with the accuracy of a mean calculated in a given sample. But we are here concerned with two populations and whether their means, determined by genetic factors, will tend to the same value as the number of polymorphic genetic factors is increased. The distributions will certainly tend to normality round the mean as the number of polymorphic factors increases: this, the central limit theorem shows. But the means would only tend to the same value if the mean gene frequencies also tended to the same value and this would happen only if similar selective forces are postulated to be operating for similar periods of time in the two populations. The law of large numbers is irrelevant to the argument.

Cavalli-Sforza and Bodmer would like to see research into IQ differences between blacks and whites stopped because they think such research can only increase racial tension. Their moral view, which almost everybody would share, is that all individuals should be given the maximum opportunity for personal development. Implicit in this is the principle that the possible biological differences between races cannot be used to make moral judgments about how the individuals of different races ought to be treated: you cannot get an " ought" from an "is ". Unfortunately it seems clear that there are some people who do not understand this basic principle of ethics: they are the people, for example, who will describe as a "racist" anybody who investigates racial differences in IQ. Suggestions that research should be suppressed because of its moral dangers may therefore tend to reinforce the fallacy in such people's minds that an "is " can entail an "ought". It would perhaps be better in the long term to get the moral philosophy right rather than to suppress research.

The great value of this book in general is its emphasis on the applications of population genetics theory to the analysis of experimental data and observations. For this, all ecological geneticists will find it useful, whether they are interested in humans, other animals or plants.

\title{
Peter O'Donald
}

Department of Genetics, University of Cambridge, Milton Road, Cambridge CB4 $1 X H$, England

ECOLOGICAL GENETICS AND EVOLUTION. Robert Creed (ed.). Blackwell, Oxford and Edinburgh, 1971. Pp. xxi+391. 66.50 .

This is a collection of essays dedicated to Professor E. B. Ford on the occasion of his seventieth birthday, and reflecting as it does the impact of his own work and teaching on the development of so important a branch of genetics it must be a source of great pleasure and pride to Professor Ford. I would like to add my own congratulations and good wishes to those of the twentyfour contributors to this volume.

Like all such collections put together to mark an occasion, the nineteen papers it contains are somewhat mixed in their approaches, their aims, and their subject material. They mostly deal with animals, with Lepidoptera and snails not surprisingly well to the fore; but four of them are concerned with human polymorphism to which Professor Ford directed attention a quarter of a century ago. Indeed, the whole volume reflects Professor Ford's 
interest in polymorphisms and his emphasis on the need for their study in the wild as well as the laboratory-a study which has given them a central place in ecological genetics as we have seen it grow up.

It is a pleasure to see contributions from G. D. Darlington and Th. Dobzhansky, the former examining the almost paradoxical causes and consequences of polymorphisms and the latter reviewing the changes over time of the inversion polymorphisms in Drosophila pseudo-obscura; changes which are so very clear, so obviously not random, and yet so bewildering to interpret. It would however, be too lengthy a task to comment individually on all nineteen papers and their contents, and at the risk of being inviduous in choosing among them, I will refer specifically to only two more. A. D. Bradshaw's account of the response of certain plants to extreme environments offers striking examples of selective changes observable in the wild, where the selective forces are clear, and shows us how powerful relatively simple techniques can be in revealing the effects not only of the selective forces but also of such things as gene exchange by the wind drifting of pollen. In another striking paper L. P. Brower, J. Alcock, and J. V. Z. Brower describe an experiment on bird predation of butterflies which removes one's doubts about the prospective selective advantage of the first moves in appearance of a mimic towards its model, and in so doing fill in a troublesome gap in our understanding of how mimicry is built up by selection. Several papers deal with melanism and, in respect of industrial melanism, bring out the problems of its detailed interpretation in relation to that complex of changes which go to make up industrial pollution. Others cover a wide variety of subjects ranging from the variation of fitness with size in snails to the analysis and representation of spotting patterns on butterflies' wings. A number of them list extensive data which are prospectively valuable to have on record even though their interpretation is not obvious in anything but the broadest outline.

Like all such volumes, this is one which will hold different interests for different people. Its place is probably in departmental collections rather than individual libraries; but it is a book to which anyone interested in natural populations, their genetics and their polymorphisms will wish to have access for reference.

It is noteworthy, too, for the review that it excited from Professor R. G. Lewontin (Nature, 236, 181-182, 1972). This is itself an essay, and a provocative one, on the intrinsic nature of the theory of evolution by natural selection and the significance of ecological genetics in relation to it. $\mathrm{He}$ starts off from Karl Popper's analysis of science and in particular his criticism of the theory of evolution. He disposes of the criticism that the history of living organisms is a series of unique events and therefore cannot lead to generalisations, by pointing out that for many purposes one species is like another so that there is an essential replication of events to be obseved, which allows certain types of generalisation to be sought. He then goes on to say that the verification of the theory of evolution by natural selection must rest on the success with which observable variation between organisms can be related to identifiable environmental circumstances, which is of course one of the prime purposes of ecological genetics. He concludes that while interpretation in terms of natural selection has had its successes, notably with mimicry, it has had its failures also, for example with human blood groups, so leaving the issue still in doubt. 
While agreeing with much that he says, I believe that Professor Lewontin has understated the case for natural selection. That it occurs and in doing so changes wild populations in forecastable ways cannot be in doubt; the impact of antibiotics on bacteria, of insecticides on flies, of heavy metals on plant communities, bear ample witness to its working, as does the mimicry which he quotes. To go still wider, and it may be thought beyond the field of ecological genetics, the notion of natural selection is implicit in our understanding of such things as genetic systems, the genetical structures and consequences of the wealth of diverse breeding systems in plants, genetic balance in inbreeders and outbreeders, and the genetical architecture of characters. It also enables us to understand the various levels of genetic integration, the nature of super-genes and their growth, and it allows us even to see that a genetic mechanism can outlive its selective usefulness.

True, there is much that we cannot yet see how to interpret in terms of natural selection by directly specifiable forces. But need this be anything more than an admission, which few would deny, that we have a long way yet to go before we approach a full understanding of the organism in its habitat or the mechanisms which selection builds up? And is there any alternative view which enables us to understand and interpret even nearly as much? Neutral genes and random drift? Drift doubtless does play its part in appropriate circumstances, and indeed there is evidence to that effect; but to ascribe the sweep of evolution to neutrality and random change is to parody a remark that the late $\mathrm{R}$. A. Fisher once made into saying "The million, million, million...to one chance happens once in a million, million, million ... times no matter how surprised we may be that it results in us". Natural selection of the character may be, as Professor Lewontin says, the essence of Darwin, but it is an essence we shall undervalue if we do not allow for its pervasiveness beyond the point of its introduction-even into molecular biology.

Referring to another part of Professor Lewontin's review, I am conscious in writing this that to the best of my knowledge I am wholly British, though I am less confident that I can claim to spring from the pre-war upper middle class to whose fascination with birds and gardens, butterflies and snails Professor Lewontin appears to attribute so much of the interest in demonstrating change by natural selection. In advancing this view, he implies a special form of selective action which would be as troublesome to substantiate as it may appear entertaining to postulate. And would it turn out to be functional or tautological selection? Or just more molecular biology?

Kenneth Mather

Department of Genetics, University of Birmingham

EVOLUTION IN PLANTS-Symposia Biologica Hungarica 12. G. Vida (ed.). Akademiai Kiado, Budapest, 1972. Pp. 231. \$9.10.

A book read avidly in the hope that it would provide a welcome addition to the limited number of useful books on this topic. One is rapidly disillusioned, and perhaps this is inevitable even had the quality of the contributions been higher; the format of a symposium is not that which lends itself to the best 